\title{
Sex Estimation from Maxillary Arch Measurements in Egyptian Populations: Cross-Sectional Study
}

\author{
Estimación Sexual a Partir de Mediciones del Arco Maxilar \\ en Poblaciones Egipcias: Estudio Transversal
}

\author{
Asmaa F. Sharif ${ }^{1,2}$; Mst. Fatema Akhter ${ }^{3}$ \& Manar M. Fayed $^{2}$
}

SHARIF, A. F.; AKHTER, M. F. \& FAYED, M. M. Sex estimation from maxillary arch measurements in Egyptian populations: Crosssectional study. Int. J. Morphol., 39(4):1224-1230, 2021.

SUMMARY: Sex estimation is an essential step in personal identification and a cornerstone for developing biological profile from skeletal remains. The present study aimed to evaluate the role of maxillary arch widths and lengths as unique parameters in the estimation of sex in Egyptian populations. Maxillary arch measurements were collected from 1410 subjects where palatal impressions were obtained from each participant. Fourteen maxillary inter-teeth widths and lengths that excluded teeth dimensions were included The current study revealed that among the studied population, Egyptian men showed significant differences $(\mathrm{p}<0.05)$ in all measurements, except widths related to the second molar, inter-second premolar length, and mesial inter-second molar length. Most of the significant sex predictors were related to the first molar. The distal inter-first molar length is the best sex predictor with the highest Area Under Curve $=0.771$, at the cut-off value $>34.57 \mathrm{~mm}$, it could predict the sex with sensitivity of $69.8 \%$, specificity of $58.8 \%$ and p<0.05. The first molar could be considered as one of the most valid and reliable teeth in estimating sex in Egyptian populations. These measurements may be used as a reference in different populations in cases of mass disaster or relevant events

KEY WORDS: Forensic odontology; Maxillary arch; Inter-first molar; Inter-second molar.

\section{INTRODUCTION}

Identification of deceased bodies and human remains is a crucial forensic issue that still represents a major dilemma in justice (Patel \& Joshi, 2016). Although DNA analysis is the most popular method in forensic identification, few countries have the budget for DNA collection and analysis following mass disasters. Sex determination is an essential step in personal identification and a cornerstone for developing biological profile from skeletal remains (Capitaneanu et al., 2017; Nagare et al., 2018). Many conditions may make the identification process a difficult mission; putrefaction is one of them, as it renders visual identification almost impossible after 24-48 h (Morgan et al., 2006). Identification by bony and dental measurements is an established method that is an easy, short responsive, accurate, and long-lasting tool (Pereira et al., 2010).

Dental measurements showed variations between men and women in different ethnic populations with men tending to have greater palatal dimensions than women of the same race (Shahin et al., 2013). These findings were observed among Nigerian, Iraqi, American, and other populations (Ibeachu et al., 2015). Various parameters were included in different studies regarding maxillary teeth measurements (Rani, 2017). Among most of them, tooth dimensions were commonly used and pointed out significant differences between men and women in the majority of previous studies (Iscan \& Kedici, 2003; Grewal et al., 2017).

However, to the best of our knowledge, no studies had been conducted to assess the sex using inter-teeth measurements with the exclusion of tooth dimensions. Moreover, local data collection is also greatly important due to the existence of ethnic differences in dental arch dimension. In forensic identification, accurate ethnicity data associated with forensic odontology are essential in informing health experts, especially the forensic odontologist Iqbal et al. (2009). The data related to dental measurement in sex estimation are not well documented in Egyptian populations.

\footnotetext{
${ }^{1}$ Clinical Medical Sciences Department, College of Medicine, Dar Al Uloom University, Saudi Arabia.

${ }^{2}$ Forensic Medicine and Clinical Toxicology Department, Faculty of Medicine, Tanta University, Egypt.

${ }^{3}$ Department of Surgical and Diagnostic Sciences, College of Dentistry, Dar Al Uloom University, Saudi Arabia.
} 
Therefore, the present study aimed to evaluate the role of maxillary arch widths and lengths, with exclusion of the teeth size, as unique parameters in sex assessment among Egyptian populations.

\section{MATERIAL AND METHOD}

Study design and setting. This is a cross-sectional study which was carried out during the period from January 1st, 2019 to January 1st, 2020. The included participants were recruited from patients who presented to outpatient's hospital department in Faculty of Medicine, Tanta University, Egypt.

Sample size. The cases involved were recruited using convenience sampling techniques to approach the largest number of participants. The current study was conducted on 1410 volunteers divided into two subgroups: the first group was composed of 890 women, and the second group consisted of 520 men.

Participants Inclusion and exclusion criteria. Adults within the age range of 18-55 years with complete maxillary dentation from central incisors to second molar teeth were included in our study. We excluded individuals with abnormal teeth number (congenitally absent teeth, deciduous tooth retention, supernumerary teeth) or shape (overjet or overbite teeth) that may affect dental arch measurements and those who have dental caries or teeth attrition that could affect the size and form of the dental arch. Moreover, patients with history of orthognathic surgery and orthodontic treatment, those who have cleft palate and/or palatal asymmetries, those who have artificial palatal grafts, Heavy calculus deposits and hypoplastic defects along cemento enamel junction and those with known allergy to impression materials were excluded.

Ethical approval and consent for participate. The current study was conducted in accordance with the ethical standards of the Declaration of Helsinki. Data collection was performed after obtaining approval of research ethical committees from the Faculty of Medicine, Tanta University, Egypt (number 33730/3/20). Furthermore, written informed consent explaining the manoeuvre and volunteer rights was obtained from each participant.

\section{Data collection tools}

Palatal impression preparation procedure. The manoeuvre was explained to the participants meeting the inclusion criteria and presented to outpatient's hospital department during the study period. Palatal impressions were obtained according to Verma et al. (2014). The volunteer's mouth was cleaned and carefully inspected to ensure its reliability in the study. In a sterilised rubber bowel, plain water was added to a measured amount of rapid set flavoured alginate powder. They were mixed with a stainless-steel spatula for 30 seconds and shaken to eliminate air bubbles, if any. The alginate paste was transferred into a suitable sized partially perforated tray. Then, the tray was inserted into the mouth and firmly pressed against the volunteer's palate for 90 seconds. During this time, subjects were asked to keep the mouth open. After complete transformation into semisolid, the impression was gently removed and washed under running water to be cleaned of saliva and debris and immediately filled with the plaster of Paris to obtain the most accurate dental cast. After hardening of the casts, they were carefully examined to exclude those with any artefacts.

Dental measurements. Under direct illumination, palatal measurements were obtained using a Vernier calliper (150$\mathrm{mm}$ calliper calibrated to $0.05 \mathrm{~mm}$ ). The measurements were obtained where the buccolingual dimensions of the teeth were excluded from the measurements as mentioned above (Ahmad, 2009). Figure 1 illustrates the maxillary arch width measurements. The inter-first premolar width (4-4) and inter-second premolar width (5-5) are the linear distances between the lingual cusp tips of the maxillary first premolars and second premolars, respectively.

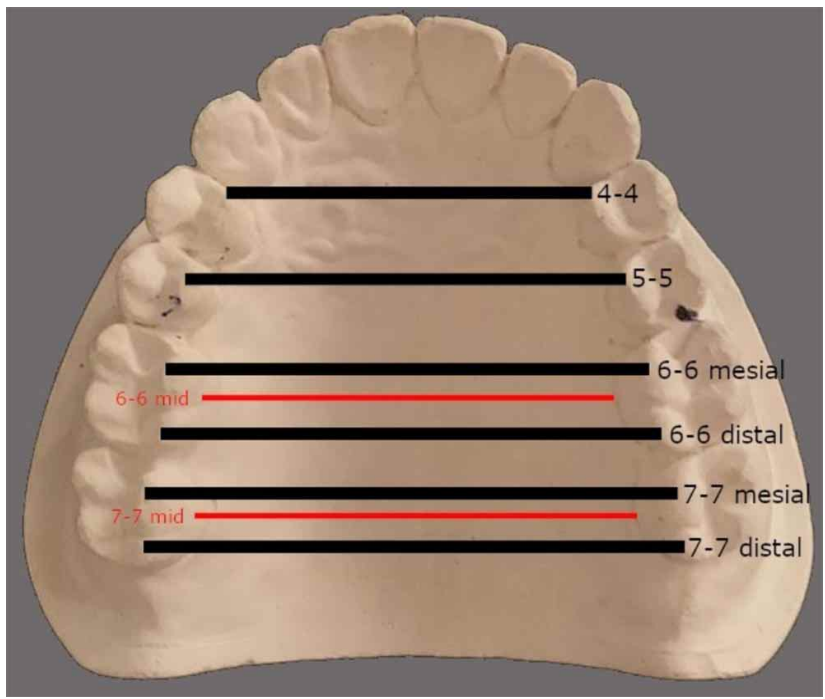

Fig. 1. Maxillary dental arch width measurements.

Regarding the molars, six measurements of the first and second maxillary molars were recorded. Concerning the first molar, the mesial inter-first molar width (6-6 mesial) is the first molars, mid inter-first molar middle width (6-6 
mid) is the linear distance between the most prominent gingivolingual points of the first molars, and lastly the distal inter-first molar width (6-6 distal) is the linear distance between the distal lingual cusp tips of the first molars (AlZubair, 2015). Regarding the second molar, the inter-second molar widths (7-7 mesial, mid, and distal) were measured in the same method conducted for the first molar (Raucci et al., 2015).

Maxillary lengths were expressed as vertical distances (1-X), where 1 refers to the point of mesial contact of upper central incisors and $\mathrm{X}$ is a point in the middle of a line representing the width between the corresponding maxillary teeth. These measurements involved six lengths. The inter-first premolar length (1-4) measured from a point of mesial contact surface of upper central incisor to the midpoint of the linear distance between the inter-first premolar width mentioned above. The inter-second premolar length (1-5) is highlighted as the line joining the point 1 with a point at the middle of the inter-second premolar width. The inter-molar lengths were coded as (16 mesial), (1-6 distal) for the inter-first molar and (1-7 mesial), (1-7 distal) for inter-second molar lengths. Both molar lengths were expressed by vertical lines passing through the point of mesial contact of upper central incisors and points at the middle of the inter-first molar width and inter-second molar width consecutively as depicted in Figure 2. Data were collected in a spreadsheet for every participant and coded with secret number. In addition to the measurement, demographic data, including age, sex, and residence for each volunteer, were recorded.

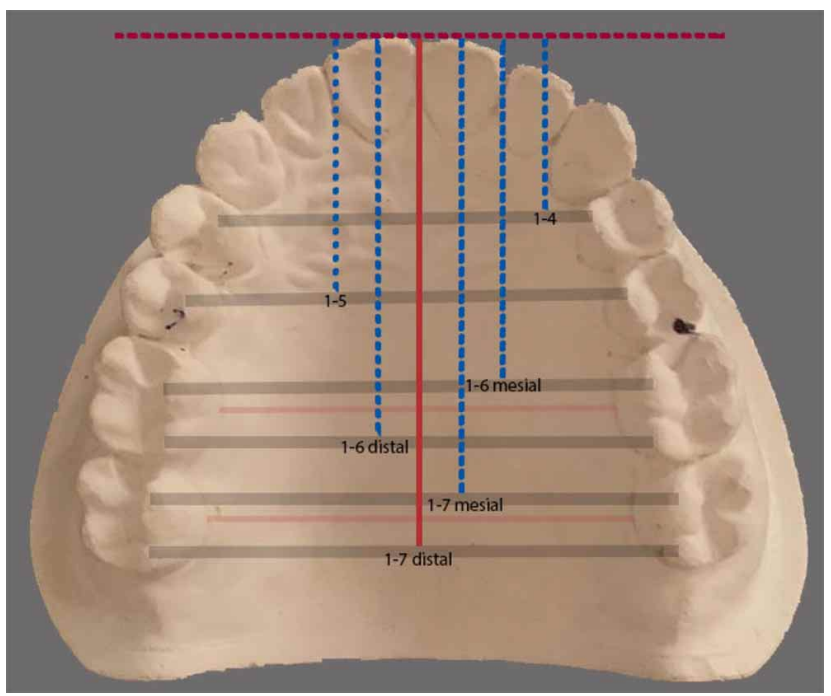

Fig. 2. Maxillary dental arch length measurements.

Method error. In order to increase the objectivity of the current study, intra-observer and inter-observer error were considered. To reduce the intra-observer error, two independent investigators recorded the measurements of 50 volunteers ( 25 males and 25 females) at two separate times with an interval of one-week. To calculate the inter-observer error, among the 50 volunteers, the studied measurements were recorded in separate spread sheets by two different assessors: A dentist and a forensic pathologist. Both, intraobserver and inter-observer error rates were calculated for the different measurements utilizing t-test. Also, we calculated the technical error of measurement (TEM) for all included measurements.

Statistical analysis. The obtained data were analyzed using the Statistical Package for the Social Sciences version 27 software program (IBM Corporation, Armonk, NY, USA). Each cohort was analyzed separately to avoid racial differences between the populations. The data were tested for normality using the Shapiro-Wilk test. The values were expressed as means and standard deviations (SDs) on $95 \%$ confidence interval. Regarding the different palatal measurements, males and females were compared using independent sample t-test. Univariate and multivariate binary logistic regression was carried out to assess the significance of different measurements as sex predictors. Receiver operating characteristic ROC curves were elaborated for the measurements showing the highest areas under curves. Permissible limit of error (alpha) of 0.05 and study power $80 \%$ were considered.

\section{RESULTS}

The results of intra-observer and inter-observer errors revealed no significant difference in all studied measurements $(p>0.05)$. TEM values were low and ranged between 0.09 and 0.25 for intra-observer error and between 0.12 and 0.39 for inter-observer error.

In the current study, women (890) constituted 63.12 $\%$ of the total participants, while men (520) represented 36.88 $\%$. Regarding the residency of studied populations, $35.3 \%$ of participants lived in urban areas, while $64.7 \%$ lived in rural areas. Furthermore, $40.1 \%$ of the included subjects were educated, while approximately $59.9 \%$ were illiterates. In addition, $30 \%$ of the participants were employed, $20.8 \%$ were housewives, $40.2 \%$ worked as farmers, and $9 \%$ did not report any working activities.

The mean age of the participants was $33.62+10.01$ years, and the range was from 18 to 55 years. The mean age did not show any significant differences between the studied groups $(p>0.05)($ mean $+\mathrm{SD}$ for women $=33.82+10.42$ years, and for men $=37.47+12.41$ and $p=0.66$ ). 
Table I depicts the different measurements among Egyptian men and women. All measurements were lengthier in men than women. This difference was significant $(p<0.05)$ in all width measurements, except those related to the second molar. Regarding the palatal lengths, all measurements, except the inter-second premolar length and mesial intersecond molar length, showed significant differences between men and women $(\mathrm{p}<0.05)$.

Table I. Maxillary arch measurements in Egyptian participants involved in the current study.

\begin{tabular}{|c|c|c|c|c|c|c|c|c|}
\hline \multirow{3}{*}{ Maxillary arch $\mathrm{r}$} & \multirow{3}{*}{$\begin{array}{c}\text { All } \\
\text { participants } \\
\mathrm{n}=1410 \\
\text { Mean+SD }\end{array}$} & \multirow{2}{*}{\multicolumn{2}{|c|}{$\begin{array}{l}\text { Men } \\
\mathrm{N}=520\end{array}$}} & \multirow[b]{2}{*}{$\begin{array}{l}\text { Women } \\
\mathrm{N}=890\end{array}$} & \multirow{3}{*}{$\mathrm{p}$} & \multirow{3}{*}{$\begin{array}{c}\text { Mean } \\
\text { differe } \\
\text { nce }\end{array}$} & \multirow{2}{*}{\multicolumn{2}{|c|}{$\begin{array}{l}95 \% \text { CI of the } \\
\text { difference }\end{array}$}} \\
\hline & & & & & & & & \\
\hline & & \multicolumn{2}{|c|}{ Mean+SD } & Mean+SD & & & Lower & Upper \\
\hline Inter-first premolar width (4-4) & $31.82+2.60$ & \multicolumn{2}{|c|}{$32.45+2.64$} & $31.45+2.52$ & $0.03 *$ & 0.99 & 0.09 & 1.89 \\
\hline Inter-second premolar width (5-5) & $36.70+3.32$ & \multirow{2}{*}{\multicolumn{2}{|c|}{$\begin{array}{l}37.67+3.71 \\
42.32 \pm 3.84\end{array}$}} & $36.05+2.88$ & $0.01 *$ & 1.62 & 0.38 & 2.86 \\
\hline Mesial inter-first molar width (6-6 mesial) & $40.92 \pm 3.65$ & & & $40.05 \pm 3.26$ & $0.00 *$ & 2.26 & 0.95 & 3.57 \\
\hline Mid inter-first molar width (6-6 mid) & $34.81 \pm 3.44$ & \multicolumn{2}{|c|}{$35.84 \pm 3.78$} & $34.24 \pm 3.12$ & $0.01 *$ & 1.60 & 0.37 & 2.83 \\
\hline Distal inter-first molar width (6-6 distal) & $43.31+3.45$ & \multicolumn{2}{|c|}{$44.31+3.97$} & $42.70+2.97$ & $0.02 *$ & 1.60 & 0.24 & 2.97 \\
\hline $\begin{array}{l}\text { Mesial inter-second molar width (7-7 } \\
\text { mesial) }\end{array}$ & $46.60 \pm 3.81$ & \multicolumn{2}{|c|}{$47.39 \pm 3.98$} & $46.12 \pm 3.65$ & 0.08 & 1.27 & 0.15 & 2.69 \\
\hline Mid inter-second molar width (7-7 mid) & $39.61+3.27$ & \multicolumn{2}{|c|}{$40.36+3.49$} & $39.14+3.05$ & 0.06 & 1.22 & 0.08 & 2.52 \\
\hline $\begin{array}{l}\text { Distal inter-second molar width (7-7 } \\
\text { distal) }\end{array}$ & $48.07+4.26$ & \multicolumn{2}{|c|}{$48.56+3.28$} & $47.76+4.79$ & 0.39 & 0.79 & 1.03 & 2.63 \\
\hline Inter-first premolar length (1-4) & $16.43+1.98$ & \multicolumn{2}{|c|}{$17.11+2.26$} & $16.03+1.69$ & $0.00 *$ & 1.08 & 0.402 & 1.75 \\
\hline Inter-second premolar length (1-5) & $23.09 \pm 2.49$ & \multicolumn{2}{|c|}{$23.59 \pm 2.70$} & $22.78 \pm 2.32$ & 0.077 & 0.81 & 0.09 & 1.70 \\
\hline $\begin{array}{l}\text { Mesial inter-first molar length (1-6 } \\
\text { mesial) }\end{array}$ & $29.95+2.85$ & \multicolumn{2}{|c|}{$30.73+2.58$} & $29.49+2.92$ & $0.02 *$ & 1.25 & 0.19 & 2.29 \\
\hline Distal inter-first molar length (1-6 distal) & $34.52+2.91$ & 35.85 & 3.01 & $33.68+2.52$ & $0.00 *$ & 2.17 & 1.12 & 3.22 \\
\hline $\begin{array}{l}\text { Mesial inter-second molar length (1-7 } \\
\text { mesial) }\end{array}$ & $40.42+3.05$ & 41.08 & 2.90 & $40.04+3.09$ & 0.08 & 1.03 & 0.13 & 2.19 \\
\hline $\begin{array}{l}\text { Distal inter-second molar length (1-7 } \\
\text { distal) }\end{array}$ & $43.84+3.15$ & 44.64 & 2.96 & $43.23+3.18$ & $0.04 *$ & 1.42 & 0.06 & 2.77 \\
\hline Sionificance at $\mathrm{n}<005 \cdot \mathrm{Cl}$ confidence in & & & & & & & & \\
\hline Maxillary arch measurement & Uni & riate lo & ic reg & gression & & Iltivariate & istic rę & ssion \\
\hline & $\mathrm{P}$ & OR & $95 \%$ & $\% \mathrm{CI}$ for OR & $\mathrm{P}$ & OR & $95 \%$ & for $\mathrm{OR}$ \\
\hline & & & Lowe & Upper & & & Lower & Upper \\
\hline Inter-first premolar width (4-4) & $0.03 *$ & 0.99 & 0.09 & 1.89 & 0.14 & 0.87 & -0.31 & 2.04 \\
\hline Inter-second premolar width (5-5) & $0.01 *$ & 1.62 & 0.45 & 2.79 & $0.03 *$ & 1.63 & 0.12 & 3.15 \\
\hline Mesial inter-first molar width (6-6 mesial) & $0.00 *$ & 2.26 & 0.95 & 3.57 & $0.00 *$ & 2.49 & 0.99 & 3.99 \\
\hline Mid inter-first molar width (6-6 mid) & $0.01 *$ & 1.60 & 0.37 & 2.83 & 0.06 & 1.61 & -0.08 & 3.29 \\
\hline Distal inter-first molar width (6-6 distal) & $0.01 *$ & 1.61 & 0.34 & 2.87 & $0.00 *$ & 2.53 & 1.05 & 4.01 \\
\hline Inter-first premolar length (1-4) & $0.00 *$ & 1.08 & 0.40 & 1.75 & $0.01 *$ & 1.25 & 0.38 & 2.13 \\
\hline Mesial inter-first molar length (1-6 mesial) & $0.02 *$ & 1.25 & 0.19 & 2.29 & $0.04 *$ & 1.29 & 0.06 & 2.54 \\
\hline Distal inter-first molar length (1-6 distal) & $0.00 *$ & 2.17 & 1.12 & 3.22 & $0.01 *$ & 1.88 & 0.55 & 3.21 \\
\hline Distal inter-second molar length (1-7 distal) & $0.04 *$ & 1.42 & 0.06 & 2.78 & 0.05 & 1.55 & 0.23 & 2.88 \\
\hline
\end{tabular}

*Significance at $\mathrm{p}<0.05 ; \mathrm{CI}$, confidence interval, OR odds ratio.

Univariate and multivariate logistic regression analysis were conducted to ascertain the effects of the nine measurements that showed significant differences between both groups on sex prediction (Table II). Out of these measurements, six measurements showed significant sex prediction $(\mathrm{p}<0.05)$. Most of the significant predictors (four out of six) were related to the first molar including the mesial inter-first molar width, the distal inter-first molar width, the mesial inter-first molar length, and the distal inter-first molar length. 
ROC curves of the six significant predictors showed that distal inter-first molar length is the best sex predictor with the highest AUC $=0.771$, at the cut-off value $>34.57$ $\mathrm{mm}$, the distal inter-first molar length could predict the sex with sensitivity of $69.8 \%$, specificity of $58.8 \%, \mathrm{p}<0.05$ as shown in Table III and Figure 3.
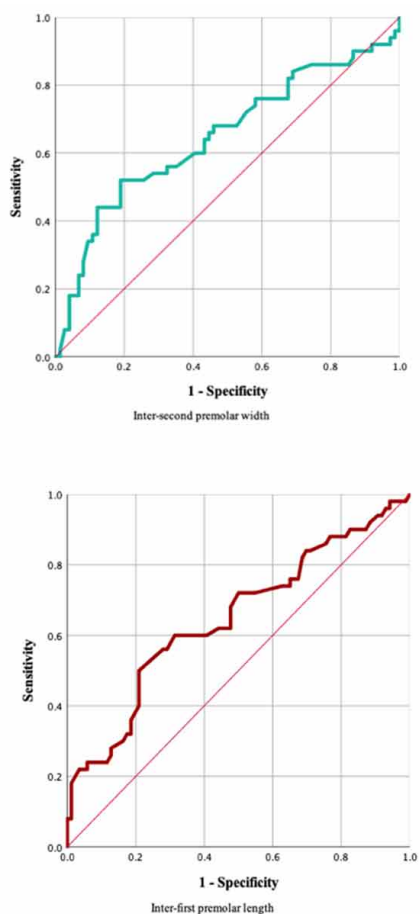

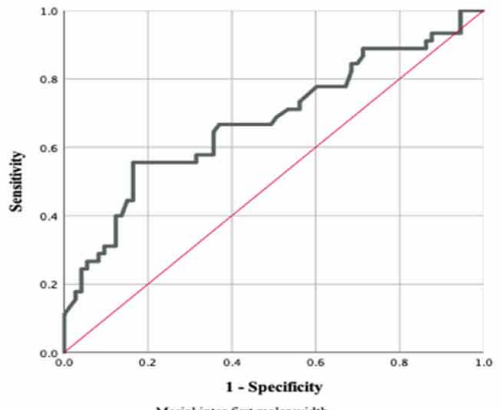

Mesial inter-fint molar width

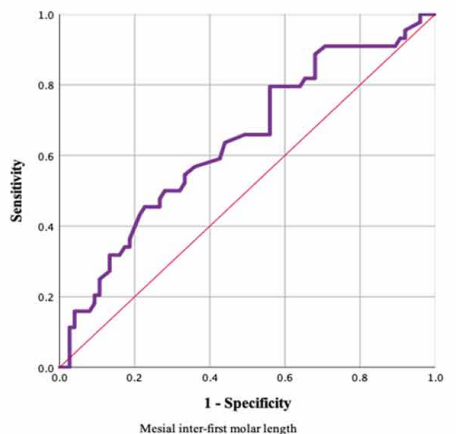

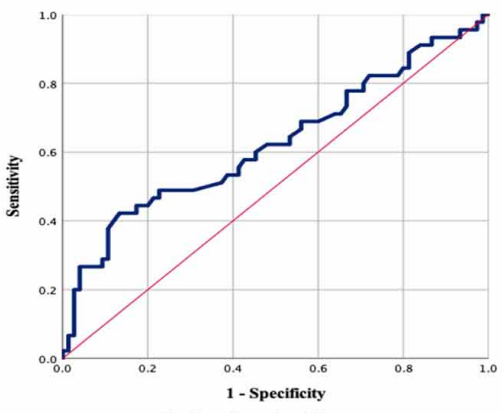

Distal inter-first molar width

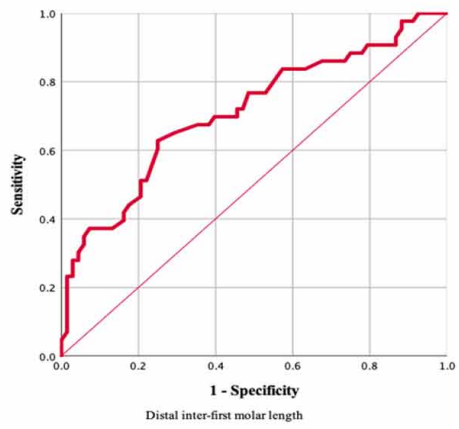

Fig. 3. Receiver operating characteristic ROC curves of the significant sex predictors in the Egyptian population.

Table III. Receiver operating characteristic ROC curves of the significant sex predictors in the Egyptian population.

\begin{tabular}{lccccc}
\hline \multicolumn{1}{c}{ Palatal measurement } & $\begin{array}{c}\text { Cutoff value } \\
(\mathrm{mm})\end{array}$ & Sensitivity & Specificity & AUC & P value \\
\hline Inter-second premolar width (5-5) & 37.13 & $56 \%$ & $66.2 \%$ & 0.647 & $0.01 *$ \\
Mesial inter-first molar width (6-6 mesial) & 41.23 & $60 \%$ & $64.4 \%$ & 0.667 & $0.01^{*}$ \\
Distal inter-first molar width (6-6 distal) & 41.9 & $57.8 \%$ & $57.3 \%$ & 0.629 & $0.02 *$ \\
Inter-first premolar length (1-4) & 16.53 & $60 \%$ & $61.6 \%$ & 0.647 & $0.00^{*}$ \\
Mesial inter-first molar length (1-6 mesial) & 30.37 & $52.3 \%$ & $66.7 \%$ & 0.639 & $0.01 *$ \\
Distal inter-first molar length (1-6 distal) & 34.57 & $69.8 \%$ & $58.8 \%$ & 0.771 & $0.00^{*}$ \\
\hline
\end{tabular}

*Significance at $\mathrm{p}<0.05$, AUC: Area Under Curve

\section{DISCUSSION}

Dental arch measurements are good identification tools due to their high resistance to trauma and putrefaction. There are increasing concerns on the use of dental arch measurements as sex predictors as they are easy and inexpensive and could be of great use in mass disasters (Narang et al., 2015). Previous studies reported significant differences in tooth size between men and women (Capitaneanu et al). Other studies implemented different dental measurements; most of them included the mesiodistal and/or buccolingual dimensions of teeth themselves within the dental arch measurement (Iscan \& Kedici; Al-Zubair) while others utilised the central fossa of molars as a reference point on both sides (Rao \& Kiran, 2016).

In the present study, we hypothesized that some palatal measurements which have been established between lingual surfaces of teeth with exclusion to the tooth size could precisely assess the sex among different populations. To the best of knowledge, the present study is the only 
prospective study conducted among Egyptian population and excluded tooth size compared with palatal measurements among men and women. In the current study, the most significant measurements that could assess sex is that of the first molar. The role of the first molar as sex predictor was mostly overlooked by the majority of previous studies, as the premolars and canines were mostly involved.

The results obtained in the current study showed that Egyptian men recorded significantly higher different dental arch measurements compared with women of the same ethnicity. These results were in agreement with other studies conducted on different populations, such as Yemeni (Al-Zubair; Turkish (Iscan \& Kedici), Chinese (Ling \& Wong, 2009), Indian (Rani), Saudi (Alkadhi et al., 2018), and Ugandan (Okori et al., 2015). They reported significant differences between men and women regarding the different palatal measurements. These findings could be attributed to the larger size of the male skeleton compared to the female skeleton, and the same might apply to the palatal lengths (Hussein et al., 2009).

Concerning the inter-molar measurements, the results obtained in the current study showed that men have significantly wider inter-first molar measurements than women regarding all inter-first molar widths. These results were in agreement with Al-Zubair, who conducted their study in Yemeni populations and reported a significant higher mesial inter-first molar width in the men compared that women. Similar results were obtained elsewhere (Rao \& Kiran). Another study conducted in India pointed out the same finding besides suggesting the maxillary interfirst molar width as a more accurate sex predictor than the maxillary inter-canine width (Bano \& Babu, 2018). AlKhatib et al. used a stereophotogrammetrical system in Southeast Asian Malays and reported similar results (AlKhatib et al., 2011). Added to the previous agreeing studies, Patel \& Joshi also reported highly significant differences in maxillary arch width and length between men and women, with men having larger measurements (Patel \& Joshi, 2016). These proposed measurements are equivalent to the inter-first molar width included in the present study.

Regarding the inter-premolar widths, the maxillary inter-first premolar widths were significantly larger in men. This was consistent with the results of two different studies conducted in the Indian populations Grewal et al. Grewal et al. reported that the inter-first premolar width (horizontal distance between buccal cusp tips of maxillary first premolar teeth on both sides) could be used as a sex predictor with good predictive value. Concerning the intersecond premolar width, the current study revealed that men showed significant wider measurements in Egyptian populations. This was similar to the finding reported in another study conducted in Ugandan (Okori et al.).

Few studies supported combining both inter-molar and inter-premolar widths as good sex predictors. Chinagorom et al. (2018) suggested the preference of interpremolar and inter-molar widths as sex predictors. On the same line and among the Ikwerres Nigerian population, Ibeachu et al. suggested the inter-first premolar and interfirst molar widths as sex predictors.

Concerning palatal lengths, the present study reported significant differences in some measured maxillary palatal lengths between men and women. These observations were similar to the results reported in a previously conducted study by Patel \& Joshi who documented significant lengthier interfirst molar length in men compared to that in women. In disparity with the results obtained in the current study, AlZubair reported significant differences in palatal length between Yemeni men and women; surprisingly, women recorded higher values than men. The palatal length mentioned in their study is equivalent to the distal inter-first molar length included in the current study (Al-Zubair).

Partially agreed results were obtained by Alkadhi et al., who conducted their study among the Saudi population. They mentioned significant differences between men and women regarding the inter-premolar and inter-molar widths and reported nonsignificant differences between both sexes, regarding all measured maxillary palatal lengths (Alkadhi et al.). As previously mentioned, these differences might be attributed to the different ethnicities.

\section{CONCLUSIONS}

In the Egyptian populations, men showed significant higher palatal widths and lengths than women of the same ethnicity. Excluding the mesiodistal and buccolingual dimensions of the teeth, the inter-first molar dimensions, especially the distal inter-first molar, length could be utilised as reliable sex predictors with acceptable degree of accuracy. The current study recommends studying the role of first molar in sex assessment in other populations.

\section{ACKNOWLEDGMENTS}

The authors extend their appreciation to the Deanship of Postgraduate and Scientific Research at Dar Al-Uloom University for funding this work. 


\section{FUNDING}

This research was funded by Deanship of Postgraduate and Scientific Research at Dar Al-Uloom University and "The APC was funded by Deanship of Postgraduate and Scientific Research at Dar Al-Uloom University".

SHARIF, A. F.; AKHTER, M. F. \& FAYED, M. M. Estimación sexual a partir de mediciones del arco maxilar en poblaciones egipcias: Estudio transversal. Int. J. Morphol., 39(4):1224-1230, 2021

RESUMEN: La estimación del sexo es un aspecto esencial en la identificación personal para desarrollar el perfil biológico a partir de restos óseos. El presente estudio tuvo como objetivo evaluar el papel del ancho y longitud del arco maxilar como parámetros únicos en la estimación del sexo en poblaciones egipcias. Se obtuvieron medidas del arco maxilar de 1410 sujetos, además de las impresiones palatinas de cada participante. El estudio actual reveló que entre la población estudiada, los hombres egipcios mostraron diferencias significativas ( $p<0.05$ ) en todas las medidas, excepto en el ancho relacionado con el segundo molar, longitud entre el segundo premolar y longitud entre segundo molar mesial. La mayoría de los predicciones significativas de sexo se relacionaron con el primer molar. La longitud interprimer molar distal es el mejor predictor de sexo con el Área Bajo Curva más alta $=0,771$, en el valor de corte $>34,57 \mathrm{~mm}$, podría predecir el sexo con sensibilidad de $69,8 \%$, especificidad de $58,8 \%$ y $\mathrm{p}<0,05$. El primer molar podría considerarse como uno de los dientes más confiables para estimar el sexo en las poblaciones egipcias. Estas mediciones se pueden utilizar como referencia en diferentes poblaciones en casos de desastres masivos o eventos relevantes.

PALABRAS CLAVE: Odontología forense; Arco maxilar; Interprimer molar; Inter-segundo molar.

\section{REFERENCES}

Ahmad, Z. M. Palatal dimensions and its correlation with the circumference of upper anterior teeth. Al-Rafidain Dent. J., 9(2):259-67, 2009.

Al-Zubair, N. M. Determinant factors of Yemeni maxillary arch dimensions. Saudi Dent. J., 27(1):50-4, 2015.

Al-Khatib, A. R.; Rajion, Z. A.; Masudi, S. M.; Hassan, R.; Anderson, P. J. \& Townsend, G. C. Tooth size and dental arch dimensions: a stereophotogrammetric study in Southeast Asian Malays. Orthod. Craniofac. Res., 14(4):243-53, 2011.

Alkadhi, O. H.; Almahfouz, S. F.; Tokhtah, H. A. \& Binhuwaishel, L. A. Dental arch dimensions in Saudi adults. Int. J. Dent., 2018:2190250, 2018.

Bano, A. M. \& Babu, K. Y. Comparison of intercanine and intermolar width of the maxilla as an aid in gender determination: A preliminary study. Drug Invent. Today, 10 Special Issue 3:3149-52, 2018.

Capitaneanu, C.; Willems, G.; Jacobs, R.; Fieuws, S. \& Thevissen, P. Sex estimation based on tooth measurements using panoramic radiographs. Int. J. Legal Med., 131(3):813-21, 2017.

Chinagorom, P. I.; Chidozie, A. V. \& Aperepikiya Tom, A. Sex estimation by odontometric study of the maxillary canine teeth using discriminant function analysis. Dentistry, 8(6):1000493, 2018.

Grewal, D. S.; Khangura, R. K.; Sircar, K.; Tyagi, K. K.; Kaur, G. \& David, S. Morphometric analysis of odontometric parameters for gender determination. J. Clin. Diagn. Res., 11(8):ZC09-ZC13, 2017.
Hussein, K. W.; Rajion, Z. A.; Hassan, R. \& Noor, S. N. F. M. Variations in tooth size and arch dimensions in Malay schoolchildren.Aust. Orthod. J., 25(2):1638, 2009.

Ibeachu, P. C.; Aigbogun, E. Jr.; Didia, B. C. \& Fawehinmi, H. B. Determination of sexual dimorphism by odontometric study using discriminant function analysis of adult Ikwerre dental cast. Sch. J. App. Med. Sci., 3(4B):1732-8, 2015.

Iqbal, G.; Gumber, A.; Johnson, M. R. D.; Szczepura, A.; Wilson, S. \& Dunn, J. A. Improving ethnicity data collection for health statistics in the UK.Divers. Equal. Health Care, 6, 2009.

Iscan, M. Y. \& Kedici, P. S. Sexual variation in bucco-lingual dimensions in Turkish dentition. Forensic Sci. Int., 137(2-3):160-4, 2003.

Ling, J. Y. K. \& Wong, R. W. K. Dental arch widths of Southern Chinese. Angle Orthod., 79(1):54-63, 2009.

Morgan, O. W.; Sribanditmongkol, P.; Perera, C.; Sulasmi, Y.; Van Alphen, D. \& Sondorp, E. Mass fatality management following the South Asian tsunami disaster: case studies in Thailand, Indonesia, and Sri Lanka. PLoS Med., 3(6):e195, 2006.

Nagare, S. P.; Chaudhari, R. S.; Birangane, R. S. \& Parkarwar, P. C. Sex determination in forensic identification, a review. J. Forensic Dent. Sci., 10(2):61-6, 2018.

Narang, R. S.; Manchanda, A. S. \& Singh, B. Sex assessment by molar odontometrics in North Indian population. J. Forensic Dent. Sci., 7(1):54-8, 2015.

Okori, H.; Apolot, P. S.; Mwaka, E.; Tumusiime, G.; Buwembo, W. \& Munabi, I. G. A secondary analysis to determine variations of dental arch measurements with age and gender among Ugandans. BMC Res. Notes, 8:428, 2015.

Patel, N. \& Joshi, M. Evaluation and comparative study of palatal rugae, arch length, and arch width with its predictive accuracy for Gender Identification. J. Pierre Fauchard Acad. (India Section), 30(2):42-6, 2016.

Pereira, C.; Bernardo, M.; Pestana, D.; Santos, J. C. \& de Mendonçda, M. C. Contribution of teeth in human forensic identification--discriminant function sexing odontometrical techniques in Portuguese population. J. Forensic Leg. Med., 17(2):105-10, 2010.

Rani, S. T. Applicability of odontometric dimensions and indices in sexual dimorphism among Nalgonda population. J. Forensic Dent. Sci., 9(3):175, 2017.

Rao, G. V. \& Kiran, G. Sex determination by means of inter-canine and inter-molar width- a study in Telangana population. Asian Pac. J. Health Sci., 3:171-5, 2016.

Raucci, G.; Pachêco-Pereira, C.; Grassia, V.; d'Apuzzo, F.; Flores-Mir, C. \& Perillo, L. Maxillary arch changes with transpalatal arch treatment followed by full fixed appliances. Angle Orthod., 85(4):683-9, 2015.

Shahin, K. A.; Chatra, L. \& Shenai, P. Dental and craniofacial imaging in forensics. J. Forensic Radiol. Imaging, 1(2):56-62, 2013.

Verma, K. G.; Verma, P.; Bansal, N.; Basavaraju, S.; Sachdeva, S. K. \& Khosa, R Correlation of palatal rugoscopy with gender, palatal vault height and $\mathrm{ABO}$ blood groups in three different Indian populations. Ann. Med. Health Sci. Res., 4(5):769-74, 2014.

Corresponding author:

Dr. Asmaa Fady Sharif

Clinical Medical Sciences Department

College of Medicine

Dar Al Uloom University

Al-Falah, Riyadh 13314

SAUDI ARABIA

E-mail: asma.s@dau.edu.sa

ORCID ID: https://orcid.org/0000-0002-6104-562X

Received: 08-04-2021

Accepted: 16-05-2021 